\title{
Energy and exergoeconomic analysis of the gas compression station: A case study
}

\author{
Mohammad Javadzadeh $^{1, a}$, Shahram Khalilarya ${ }^{1}$, Samad Jafarmadar ${ }^{1}$ \\ AND BABAK AMIRKAMVAR ${ }^{2}$ \\ 1 Department of Mechanical Engineering, Urmia University, 0098, Urmia, Iran \\ 2 National Iranian Gas Company, Gas Transmission Operation Destination 8, Iran
}

Received 25 October 2014, Accepted 5 January 2015

\begin{abstract}
The aim of this study is to improve the gas turbine operating conditions, used in the gas compression station of Marand, from the energy, exergy and economic points. The most important problems of these turbines are the low thermal efficiency due to the high heat losses, consuming large amounts of natural gas at the gas turbine start-up time in the starter system, turbine dependence on external electrical energy sources, as well as the high costs of fuel supply for the turbine and power consumption in auxiliary equipments. In this study the application of heat recovery steam generator to reduce the heat losses and increase the efficiency of combined cycle besides the replacement of the inefficient existing starting system are suggested. Furthermore, the effects of inlet air temperature, load, pinch point and steam injection to the turbine combustor are investigated in the energy and exergy balance equations and the unit exergy cost rates. Moreover, the costs related to the start up of a gas turbine, the fuel consumption and electrical energy are estimated. Results reveal that suggestive system not only can make the gas compression station independent from the external energy sources, but it also can reinforce the efficiency of the system and reduce the carrying costs. As with the $0.5 \mathrm{~kg} . \mathrm{s}^{-1}$ steam injection to the combustion chamber of the gas turbine, at the inlet air temperature of $288 \mathrm{~K}$ and the pinch point of $10 \mathrm{~K}$, the efficiency of the combined cycle increases 5 percent. Also the economic saving of this suggested system is about 79.68 dollars per each functional hour of the gas turbine and for the station running in its full load and design condition the amount of economic savings will exceed to 247000 dollars in month.
\end{abstract}

Key words: Gas compression station / heat loss / exergy / heat recovery / starter turbine

\section{Introduction}

In today's world due to industrial developments and population growth the demand for energy consumption is increasing and efforts to secure energy resources and deliver it to the consumers are of the main challenges. Currently, natural gas is one of the main energy providing sources that has significant contribution in energy supply. It is needed for main industries and thermal energy consumption in domestic applications. So the role of natural gas in the industrial economy and society is revealed [1].

Delivering in time and much-needed source of energy to the end consumer has paramount importance. Today, natural gas is transported through pipelines. Along the gas pipeline due to frictions and crossing altitudes the gas pressure inside decreases. This pressure drop prevents the gas to move forward along pipeline. To compensate for

\footnotetext{
${ }^{a}$ Corresponding author: mjavadzadeh2007@gmail.com
}

the pressure drop, gas compression stations along the gas pipelines are used. In gas compression station using centrifugal compressors the pressure of gas through pipeline increases. The driving force of these compressors is provided from the gas turbines which are coupled to them. The most important energy consumptions in gas compression stations are fuel consumption in gas turbines, electrical power consumption of the turbine equipments, electrical power consumption in air coolers to cool down the high-pressure compressed natural gas and the high temperature lubrication oil, natural gas consumption in expansion starter turbine and electrical power consumption in the electric heater to increase the temperature of the turbine fuel.

Some of the major problems of the existing system are mentioned below:

(1) In the studied gas compression station the thermal efficiency of the gas turbines is approximately $30 \%$ and this means that about $70 \%$ of the fuel energy is 


\section{Nomenclature}

\begin{tabular}{|c|c|c|c|}
\hline$P$ & Pressure (bar) & $Z$ & Purchase cost of the component (\$) \\
\hline$T$ & Temperature (K) & LHV & Low heat value $\left(\mathrm{kj} \mathrm{kg}^{-1}\right)$ \\
\hline$\dot{W}$ & Power $(\mathrm{kW})$ & $\dot{Z}$ & Capital cost flow $\left(\$ \cdot h^{-1}\right)$ \\
\hline$\dot{m}$ & Mass flow $\left(\mathrm{kg} \cdot \mathrm{s}^{-1}\right)$ & & \\
\hline$C_{\mathrm{P}}$ & Specific heat at constant pressure $\left(\mathrm{kj} \cdot \mathrm{kg}^{-1} \cdot \mathrm{K}^{-1}\right)$ & \multicolumn{2}{|r|}{ Subscripts and abbreviations } \\
\hline$S$ & Entropy $\left(\mathrm{kj} \cdot \mathrm{kg}^{-1} \cdot \mathrm{K}^{-1}\right)$ & $\mathrm{a}$ & Actual \\
\hline$I$ & Irreversibility $(\mathrm{kW})$ & $\mathrm{s}$ & Isentropic \\
\hline$\eta$ & Efficiency & $\mathrm{g}$ & Gas \\
\hline$h l$ & Heat loss percent $(-)$ & $\mathrm{D}$ & Destruction \\
\hline$\gamma$ & Specific heat ratio & LPT & Low pressure turbine \\
\hline$\varphi$ & Operating and maintenance factor & HPT & High pressure turbine \\
\hline$\dot{E}_{x}$ & Working fluid exergy $(\mathrm{kW})$ & comp & Compressor \\
\hline$C R F$ & Capital recovery factor & GT & Gas turbine \\
\hline$p p$ & Pinch point $(\mathrm{K})$ & st & Steam turbine \\
\hline$h$ & Working fluid enthalpy (kj.kg $\left.{ }^{-1}\right)$ & HRSG & Heat recovery steam generator \\
\hline
\end{tabular}

excreted to the environment without any use as an exhaust heat loss.

(2) The heat losses from the walls of the gas turbine combustion chamber are considered of other problem that reduces the system efficiency and leads to deployment and installation of auxiliary equipments for turbine cabin cooling and this increases the electrical power consumption of the gas turbine.

(3) There from in gas turbines, natural gas is usually used as the fuel, so the cost of this fuel supply is high.

(4) The existing expansion starter turbine discharges large amount of natural gas into the atmosphere. Due to the high costs to explore, refine and deliver the natural gas to end users, this amount of natural gas discharging into environment causes huge losses in financial assets and energy resources and also environmental pollutions.

(5) Dependence of the existing system to electrical power consumption in air coolers, electrical heater and blower fans is one of the major weaknesses of the gas compression stations in a way that in the event of power failure, the unit will stop working.

One of the most effective ways to prevent heat losses in gas turbines is to use heat recovery steam generator system. In this system by the thermal energy of the turbine exhaust gases, steam is generated and is used in steam turbine to produce electrical power. This can be an excellent source of electrical energy supply in required gas turbine equipments and make the gas compression unit independent of external electrical energy source. In addition, the amount of produced steam can be used to increase turbine efficiency by steam injection into the combustion chamber. Some of the activities in the field of heat recovery steam generator in gas turbines are as follows.

Sue and Chuang [2] in 2004 evaluated a combined cycle of gas turbine from the perspective of second law of thermodynamics and calculated the thermodynamic second law efficiency with good accuracy. They observed that the second law efficiency of the combined cycle for the part loads became less than full load and the pinch point enhancement reduced the efficiency of the cycle.
Also cooling the entering air to the gas turbine and preheating the fuel increased its net power.

Wang et al. [3] in 2007 studied an existing simple gas turbine cycle as the basic system and converted into the modified system with either inlet air cooling and steam injection to the gas turbine. The calculated results indicated that the system with steam injection had the best efficiency improved from $29.3 \%$ to $39.9 \%$ and thus the shortest payback period, while the system with both steam injection and inlet air cooling achieved the greatest power capacity increased from 52.1 MW to 96.8 MW.

Yang et al. [4] in 2009 investigated thermodynamically the influences of inlet air cooling using an absorption chiller system in a combined cycle of gas turbine over the efficiency and net power and estimated the resulting savings in power generation in a non-cooling cycle and in the proposed new cycle.

Lee et al. [5] in 2010 investigated the effects of simultaneous injection of water and steam into the combustion chamber of a gas turbine in a combined cycle of gas turbine. The most important results of this study can be noted to increase in the efficiency and net power in a combined cycle with steam injection to the turbine combustor.

Basrawi et al. [6] in 2011 investigated the effects of environmental temperature on the performance of combined cycle of gas turbine in areas with cold climates and achieved the following results:

1. Electrical efficiency decreased with increasing ambient temperature.

2. With increasing temperature the amount of heat recovered from the exhaust gases increased.

3. The fraction of heat recovery to produced power, increased with increasing ambient temperature.

Carazas et al. [7] in 2011 studied the capability of heat recovery system efficiency in a combined cycle power plant.

Sayyaadi and Mehrabipour [8] in 2012 investigated the second law efficiency of a gas turbine cycle by using a heat exchanger in the turbine exhaust and reheating the intake air. Then they calculated the time of investment return after installing heat exchanger in three different 
ambient temperatures. The second law of thermodynamics decreased with increasing ambient temperature and the time of investment return also increased.

Maya and Kribus [9] in 2012 proposed a plan that uses solar energy and thermal energy of the exhaust gases, to produce steam. Then steam was injected into the combustion chamber. In this study it was shown that increasing the mass fraction of water vapour in the entering air to the combustion chamber increases the power output of the turbine. The maximum contribution of solar energy to provide the heat needed for steam generation is $50 \%$ and a maximum efficiency in this system is $37 \%$.

Ganjeh Kaviri et al. [10] in 2013 studied the combined cycle power plant with HRSG dual pressure and firing system. The effects of HRSG inlet gas temperature on the steam cycle efficiency and $\mathrm{CO}_{2}$ emission were investigated in this research. The results revealed that increasing HRSG inlet gas temperature led to increase in the thermal efficiency and exergy efficiency of the cycle until $650{ }^{\circ} \mathrm{C}$ and after that decreased. Also from the exergy analysis of HRSG, it was cleared that the HP-EV and 2st HP-SH have the most exergy destruction respectively.

Feng et al. [11] in 2014 discussed about the dual pressure HRSG with three different layouts of Taihu Boiler with specified values of inlet temperature, composition of flue gas, mass flow rate and water/steam parameters as temperature, pressure, steam mass flow rate and heat efficiency of different heat exchangers layout of HRSG. Analysis was based on the laws of thermodynamics and energy balance equations for the heat exchangers. The results of the steam mass flow rate, heat efficiency obtained for three heat exchangers layout of HRSGs and compared with each other. It was found that the optimization of heat exchangers layout of HRSGs has a great significance for waste heat recovery and energy conservation.

Although there are some papers about heat recovery systems in gas turbines in literature, but they have not investigated the use of this system in gas compression stations and there is not any specific research about the effects of inlet air temperature, steam injection and pinch point on the amount of total energy savings, plant efficiency, irreversibilities and economic savings and investment return rate in real operating conditions of these plants. Also there is not specific research about the economic analysis of replacing the existing gas turbine starting system with other alternatives.

The aim of this work is to evaluate the gas compression station installed in Marand city from the point of energy, exergy and exergoeconomic view with an approach to reduce energy consumptions and costs. In this station there are five gas turbines in parallel formation which supply the driving forces of the gas compressors. These gas turbines are the major consumers of energy in this plant. Due to the low efficiency of the gas turbines, large amounts of energy are wasted through exhaust gasses. Furthermore, the starting system of the existing gas turbine is a kind of expansion turbine, with the natural gas working fluid which ends large amounts of natural gas into the atmosphere during turbine start up and adds the inefficiency of the existing system.

In this research the use of exhaust gases thermal energy is investigated to produce steam and electrical power. This free extra electrical power can be used in electrical facilities of the gas turbine unit and the gas compression station can be independent from foreign electrical energy sources. In addition the effects of inlet air temperature, steam injection to the combustion chamber and the pinch point are studied on the combined cycle performance parameters including fuel consumption, net power production, irreversibilities, economic savings and investment return. Moreover, the possibility of replacing the existing gas turbine starter system is considered. For this purpose a comprehensive thermodynamic model for the total suggestive gas compression station with all equipments including gas turbine, gas compressor, air coolers and heat recovery steam generator has been developed. This model is capable of providing all the predictions of the gas compressor power consumption, gas turbine power production, gas turbine exhaust temperature, electric power production out of the exhaust gases thermal energy and the amount of heat transfer in all the existing equipments in different working conditions of the gas compressor and governing climate conditions. In addition, it is capable of investigating exergy destructions and second law efficiencies of various components of the system equipments and the factors affecting them.

\section{Description of the existing gas compression station}

The studied gas compression station has been formed out in four main parts consisting of turbines fuel temperature and pressure control unit, gas turbine and gas compressor, filters and cooling airs. Figure 1 schematically shows the configuration of the existing station. Natural gas is received via two different points out of gas transport pipeline and enters in to the plant. At first, the fuel gas is being conditioned including filtration, pressure regulation and temperature adjustment. This gas is used in other components of the station such as expansion starter turbine, buildings and emergency power generator. In the next phase natural gas passes through the filter and then enters into the gas compressor. The compressed high pressure natural gas cools down in air coolers and finally is delivered to the pipeline.

Tables 1 and 2 have summarized the most important energy consumptions and performance parameters in the present plant respectively.

\section{Proposed gas compression station}

As shown in Figure 1 in the gas compression station, hot exhaust gases of the gas turbine, with the temperature of about $480^{\circ} \mathrm{C}$ in station's nominal load are sent into the atmosphere. On the other hand an expansion turbine is 


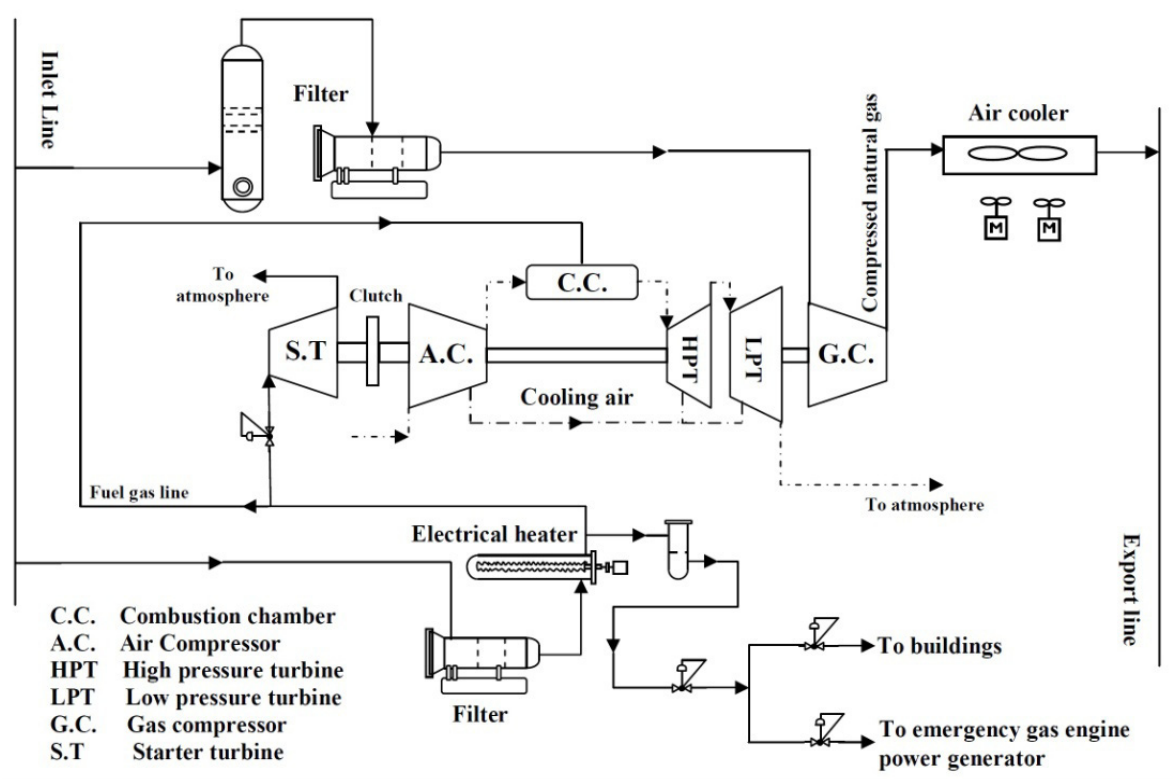

Fig. 1. General scheme of the studied gas compression station.

Table 1. Energy consumptions for the existing gas turbine auxiliary equipments.

\begin{tabular}{cccc}
\hline Equipment type & Unit & $\begin{array}{c}\text { Energy consumption } \\
\text { in full load }\end{array}$ & $\begin{array}{c}\text { Energy consumption } \\
\text { in minimum load }\end{array}$ \\
\hline Gas coolers & $\mathrm{kW}$ & $37^{*} 4$ & $37^{*} 1$ \\
Ventilation fans & $\mathrm{kW}$ & $26^{*} 2$ & $11.1^{*} 2$ \\
Oil coolers & $\mathrm{kW}$ & $8.8^{*} 2$ & $2.2^{*} 2$ \\
Oil vapour separator & $\mathrm{kW}$ & 5.5 & 5.5 \\
Electrical heater & $\mathrm{kW}$ & 27 & 12.7 \\
Total & $\mathrm{kW}$ & 250 & 81.8 \\
\hline
\end{tabular}

Table 2. Studied gas turbine performance parameters.

\begin{tabular}{cccc} 
& & & \\
\hline$T_{1} \mathrm{~K}$ & 288 & $\mathrm{P}_{2}$ bar & 12.5 \\
$T_{2} \mathrm{~K}$ & 652 & $\mathrm{P}_{5}$ bar & 1.01 \\
$T_{3} \mathrm{~K}$ & 1310 & $\eta_{\text {mech }}$ & 33.3 \\
$T_{4} \mathrm{~K}$ & 994 & Turbine net power MW & 11.5 \\
$T_{5} \mathrm{~K}$ & 775 & Gas compressor max power MW & 7.9 \\
$P_{1}$ bar & 1.01 & & \\
\hline
\end{tabular}

used to start up the gas turbine with natural gas working fluid at the temperature and pressure of the fuel gas. High pressure natural gas drives the expansion turbine and then it is vented to the atmosphere. At the moment the gas turbine is being self sustained, the starter turbine stops. In the existing starting system large amount of natural gas is lost every time the turbine is being started and this makes it inefficient and adds pollutions to the environmental as well. In this regard, the most important methods to improve of existing gas compression station and increase the efficiency of the gas turbine cycle are put forward.

1. In the case of studied gas compression station, it is necessary to note that the applied expansion starter turbine is designed primarily on the bases of steam working fluid, but in the present system without regarding to the issue, the working fluid has been changed to natural gas. This is probably due to the abundant accessibility of natural gas in these plants. The main problems of this system are the loss of large amount of gas during the turbine start up and the probability of gas leakage inside the turbine cabin and eventual explosions. In this work it is proposed to use an electrical starter to crank the air compressor of gas turbine. The electrical starter provides smooth acceleration from rest, up to a speed at which the fuel flows through the engine and provides sufficient power for the turbine to be self sustained.

2. The operation of studied gas compression station is highly related to the external electrical energy sources. In Figure 2 the proposed gas compression station and the equipments configurations are shown.

When the gas turbine is running in the full load much more energy is needed than it runs in the minimum load. It is obvious from the table, in the case of external electrical power failure the gas compression unit will stop running immediately. In the proposed system much more than this amount of energy can be produced from the exhaust gas thermal energy by employing a heat recovery steam generator. In this plan after the gas turbine reaches to the steady state operating condition the steam will be generated in the HRSG. 


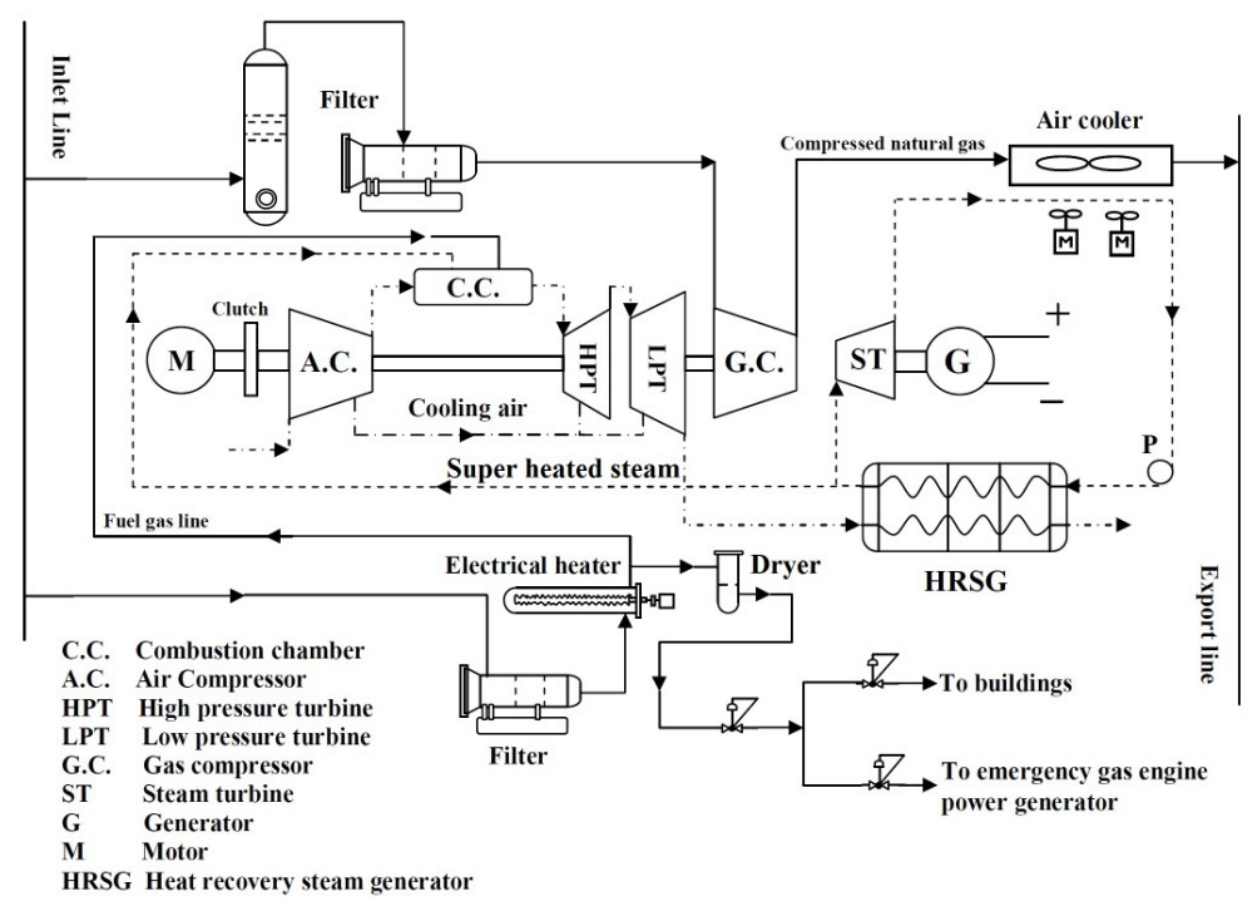

Fig. 2. Proposed system for the studied gas compression station.

This generated steam will produce power in the existing expansion steam turbine. This extra free power can be used in an electrical power generator to produce electrical energy. Thus the gas turbine unit will be independent from external electrical power sources. This generated electrical power is sufficient for the overall energy consumptions of the gas turbine auxiliary equipments.

3. A mass fraction of steam produced in the heat recovery steam generator can be injected into the combustion chamber of the gas turbine in order to increase turbine net power. It is also quite practical and executable because steam injection pipelines into the combustion chamber have already been predicted thus there is no need for a change in the structure of a gas turbine combustor.

4. On the other hand the discharged hot gasses emerging from the heat recovery steam generator can be used to increase the temperature of turbine fuel gas hence the electrical power consumption in the electric heater can be removed. Application of these improvements is only possible when the gas turbine is running and according to the special conditions of the plant, it's functioning can almost be considered uninterrupted. Therefore, the proposed system will have a good performance all year.

\section{Gas compression station modelling}

To simulate the proposed gas compression station the integrated thermodynamic model has been developed In the following, the first and second law of thermodynamic modelling of the system components are presented.

\subsection{The first law of thermodynamics}

Figure 3 shows the overview of existing gas turbine open cycle with $T$-S diagram. As indicated in the figure, the processes of compression in air compressor and expansions in both high pressure and low pressure turbines have deviancies from isentropic processes due to the irreversibilities.

\subsubsection{Air compressor}

The air compressor of the studied gas turbine is an 11 stage axial compressor with the isentropic efficiency of about 80 percents. The driving force of the air compressor is supplied from the high pressure turbine. Maximum pressure ratio of the air compressor is $15.5: 1$ and the compression process is irreversible and adiabatic. The model equations for the air compressor are as follows [12]:

$$
\begin{aligned}
\dot{W}_{\text {comp }, \mathrm{s}} & =\int_{T_{1}}^{T_{2 s}} \dot{m}_{\text {air }} C_{\mathrm{p}, \text { air }}(T) \mathrm{d} T \\
\dot{W}_{\text {comp }, \mathrm{a}} & =\int_{T_{1}}^{T_{2 a}} \dot{m}_{\mathrm{air}} C_{\mathrm{p}, \text { air }}(T) \mathrm{d} T \\
\eta_{\mathrm{i}, \mathrm{comp}} & =\frac{\dot{W}_{\text {comp }, \mathrm{s}}}{\dot{W}_{\mathrm{comp}, \mathrm{a}}} \\
\frac{P_{2}}{P_{1}} & =\left[\frac{T_{2 \mathrm{~s}}}{T_{1}}\right]\left[\frac{\gamma_{1}}{\gamma_{1}-1}\right] \\
\dot{m}_{1} & =\dot{m}_{2 \mathrm{a}}+\dot{m}_{\text {cooling air }}
\end{aligned}
$$



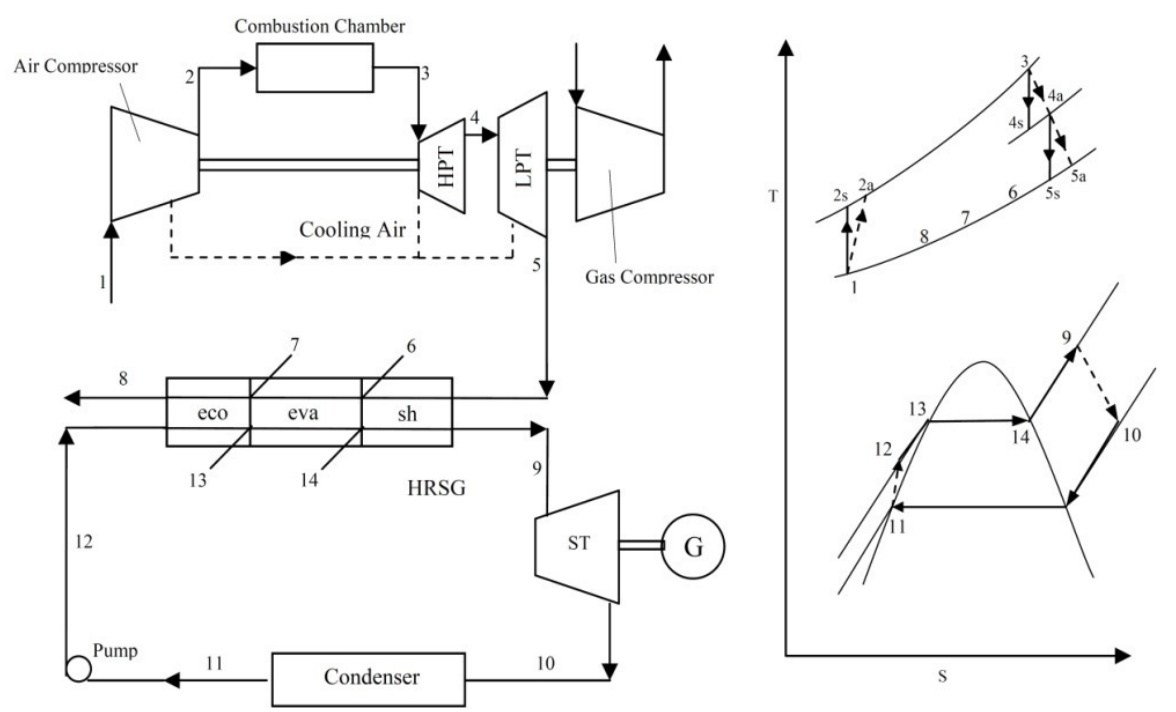

Fig. 3. Gas turbine open cycle scheme and $T-S$ diagram.

Since the air compressor discharge temperature is between 300-800 K, the heat capacity of air is obtained from relevant Equation (6) [13]:

$$
\begin{aligned}
C_{\mathrm{p}, \text { air }}=1.04841+ & \left(\frac{3.8371}{10^{4}}\right) T+\left(\frac{9.4537}{10^{7}}\right) T^{2} \\
& +\left(\frac{5.49031}{10^{10}}\right) T^{3}+\left(\frac{7.9298}{10^{14}}\right) T^{4}
\end{aligned}
$$

\subsubsection{Combustion chamber}

In the combustion chamber of the gas turbine, natural gas fuel with the lower heating value of about $50 \mathrm{Mj} . \mathrm{kg}^{-1}$ enters in to the air and the combustion process begins and the fuel energy releases. The combustion in the gas turbine is an adiabatic process with the pressure drop of about 0.2 percents of air compressor discharge pressure [14]. Inlet air to the combustor in unimproved and basic gas turbine cycle is a non-steam injected mixture. On the other hand, emissions of the nitrogen oxides are produced in the combustion chamber via the reactions between nitrogen and oxygen. The combustion modelling equations have been carried out based in Equations $(7)-(9)$ :

$$
\begin{gathered}
\dot{m}_{\text {fuel }}(\mathrm{LHV})_{\text {fuel }}=\left(\dot{m}_{\mathrm{g}}\right) C_{\mathrm{p}, \mathrm{g}}\left(T_{3}\right) \cdot T_{3}-\dot{m}_{\mathrm{air}} C_{\mathrm{p}, \text { air }}\left(T_{2, \mathrm{a}}\right) T_{2, \mathrm{a}} \\
\dot{m}_{\mathrm{g}}=\dot{m}_{\text {air }}+\dot{m}_{\text {fuel }}
\end{gathered}
$$

According to the hot gasses temperature range in the combustion chamber which is between $800-2200 \mathrm{~K}$, so the heat capacity is obtained out of Equation (9) [13]:

$$
\begin{aligned}
C_{\mathrm{p}, \mathrm{g}} & =0.991615+\left(\frac{6.99703}{10^{5}}\right) T+\left(\frac{2.7129}{10^{7}}\right) T^{2} \\
& -\left(\frac{1.22442}{10^{10}}\right) T^{3}
\end{aligned}
$$

\subsubsection{High and low pressure turbines}

Hot gasses of the combustion chamber initially enter into the high pressure turbine and then pass through the low pressure one. Both turbines isentropic efficiencies are about 82 percents. The driving forces of the air compressor and the gas compressor are provided via high pressure and low pressure gas turbines respectively. Both turbines' expansion processes are considered irreversible and adiabatic. The equations of the gas turbines modelling are as follows $[15]$ :

$$
\begin{aligned}
\dot{W}_{\mathrm{HPT}, \mathrm{a}} & =\int_{T_{3}}^{T_{4 a}}\left(\dot{m}_{\mathrm{g}}\right) C_{\mathrm{p}, \mathrm{g}}(T) \mathrm{d} T \\
\dot{W}_{\mathrm{LPT}, \mathrm{a}} & =\int_{T_{4 a}}^{T_{5 a}}\left(\dot{m}_{\mathrm{g}}\right) C_{\mathrm{p}, \mathrm{g}}(T) \mathrm{d} T \\
\eta_{\mathrm{i}, \mathrm{turb}} & =\frac{\dot{W}_{\mathrm{turb}, \mathrm{a}}}{\dot{W}_{\mathrm{turb}, \mathrm{s}}} \\
\frac{p_{4 \mathrm{a}}}{p_{3}} & =\left(\frac{T_{4 \mathrm{~s}}}{T_{3}}\right)^{\left(\frac{\gamma_{3}}{\gamma_{3}-1}\right)} \\
\frac{p_{5 \mathrm{a}}}{p_{4}} & =\left(\frac{T_{5 \mathrm{~s}}}{T_{4}}\right)\left(\frac{\gamma_{4}}{\gamma_{4}-1}\right) \\
p_{3} & =p_{2}-0.02 p_{2}
\end{aligned}
$$

\subsubsection{Heat recovery steam generator (HRSG)}

The HRSG system consists of three sections including economizer, evaporator and super heater. In this system hot gasses and steam, flow in opposite directions. Thus, hot gasses cross over the super heater, evaporator and the economizer respectively. The temperature and pressure ranges of steam generator are set on the bases of the expansion steam turbine performance parameters. According to the amount of steam production in the steam 
Table 3. Steam turbine specifications* .

\begin{tabular}{ccc}
\hline Parameter & Unit & Value \\
\hline maximum power generation & $\mathrm{kW}$ & 746 \\
Maximum inlet pressure & $\mathrm{bar}$ & 46 \\
Maximum inlet temperature & $\mathrm{K}$ & 713 \\
Maximum outlet pressure & $\mathrm{bar}$ & 11 \\
Maximum speed & $\mathrm{rpm}$ & 4300 \\
Inlet diameter & $\mathrm{mm}$ & 100 \\
Exhaust diameter & $\mathrm{mm}$ & 200 \\
\hline
\end{tabular}

* Available at: www.dresser-rand.com/products/steam/ singlestage/rla.php.

generator, a mass fraction of the steam is injected into the combustion chamber in the proper pressure. The combustion chamber pressure varies according to the operating condition of the gas turbine. So the steam pressure is adjusted in to the appropriate pressure. Since the steam pressure is available then the saturation temperature of the desired pressure is achievable. According to the pinch point, the hot gas temperature over the evaporator outlet is obtained. The difference between the economizer inlet and the evaporator outlet temperature is also considered negligible [16]. Employing the energy balance equation between hot gases and steam in the heat recovery steam generator, from evaporator outlet until the super heater exit, the mass flow rate of the produced steam is obtained. In order to calculate the hot gasses temperature over the super heater inlet and over the economizer inlet the corrector-predictor Equations (18) and (19) are used [16].

$$
\begin{aligned}
T_{7} & =T_{13}+P P \\
\dot{m}_{\mathrm{s}} & =\frac{\dot{m}_{\mathrm{g}}\left(C_{\mathrm{p}, 5 \mathrm{a}} T_{5 \mathrm{a}}-C_{\mathrm{p}, 7} T_{7}\right)(1-h l)}{\left(h_{9}-h_{13}\right)} \\
T_{6} & =\frac{C_{\mathrm{p}, 5 \mathrm{a}} T_{5 \mathrm{a}}}{C_{\mathrm{p}, 6}}-\frac{\dot{m}_{\mathrm{s}}\left(h_{9}-h_{14}\right)}{\dot{m}_{\mathrm{g}} C_{\mathrm{p}, 6}(1-h l)} \\
T_{8} & =\frac{C_{\mathrm{p}, 7} T_{7}}{C_{\mathrm{p}, 8}}-\frac{\dot{m}_{\mathrm{s}}\left(h_{13}-h_{12}\right)}{\dot{m}_{\mathrm{g}} C_{\mathrm{p}, 8}(1-h l)}
\end{aligned}
$$

\subsubsection{Steam turbine}

The applied steam turbine is the same starting expansion turbine mounted on the air compressor of the gas turbine. When the gas turbine is self sustained the existing automatic clutch separates the air compressor and the starter turbine and then the starter turbine stops. The existing start up turbine system is essentially a smallscale steam turbine. In the present study it is proposed to couple the starter turbine with the generator to produce electrical power after the gas turbine reaches to the steady state condition. Steam turbine specifications are presented in Table 3.

The power production in the steam turbine and the water pump power consumption are calculated using the following equations:

$$
\begin{aligned}
\dot{W}_{\mathrm{st}} & =\dot{m}_{\mathrm{st}}\left(h_{9}-h_{10}\right) \\
\dot{W}_{\text {pump }} & =\dot{m}_{\mathrm{st}}\left(h_{12}-h_{11}\right)
\end{aligned}
$$

The gas turbine and combined cycle efficiencies are obtained according to the relations (22) and (23) [17]:

$$
\begin{aligned}
\eta_{\mathrm{GT}} & =\frac{\dot{W}_{\mathrm{LPT}, \mathrm{a}}}{\dot{m}_{\mathrm{fuel}}(\mathrm{LHV})_{\mathrm{fuel}}} \\
\eta_{\text {Comined cycle }} & =\frac{\dot{W}_{\mathrm{LPT}, \mathrm{a}}+\dot{W}_{\mathrm{ST}}-\dot{W}_{\mathrm{PUMP}}}{\dot{m}_{\text {fuel }}(\mathrm{LHV})_{\text {fuel }}}
\end{aligned}
$$

\subsection{Second law of thermodynamics}

Exergy analysis of thermodynamic systems helps to improve the ways of energy use in them. Accordingly exergy studies in many systems especially in combined cycle power generation are expanding rapidly. In general exergy consists of four main components of chemical, physical, kinetic and potential exergy. Since the little altitude and speed changes, potential and kinetic exergies are neglected [17]. The physical exergy is defined based on the maximum obtainable work of the system in contact with the environment. The chemical exergy is the chemical potential between the existing and the equilibrium compounds. Using the second law of thermodynamics the exergy balance equation is written as relations (24)-(27):

$$
\begin{aligned}
\dot{E} x_{\mathrm{Q}}+\sum_{i} \dot{m}_{i n} e x_{i n} & =\sum_{e} \dot{m}_{\mathrm{out}} e x_{\mathrm{out}}+\dot{E} x_{W}+\dot{E} x_{\mathrm{D}} \\
\dot{E} x_{\mathrm{Q}} & =\left(1-\frac{T_{0}}{T_{i}}\right) \dot{Q}_{i} \\
\dot{E} x_{W} & =\dot{W} \\
e x_{\mathrm{ph}} & =\left(h-h_{0}\right)-T_{0}\left(s-s_{0}\right)
\end{aligned}
$$

In the following the exergy balance and the second law efficiency equations are written for air compressor, combustion chamber, gas turbine and heat recovery steam generator respectively [18].

Air compressor exergy

$$
\begin{aligned}
\dot{m}_{\text {air }} e x_{1}+\dot{W}_{\text {comp }, \mathrm{a}} & =\dot{m}_{\text {air }} e x_{2 \mathrm{a}}+I_{\text {comp }} \\
\eta_{\mathrm{II}, \mathrm{comp}} & =1-\frac{I_{\mathrm{comp}}}{\dot{W}_{\mathrm{comp}, \mathrm{a}}}
\end{aligned}
$$

Combustor exergy

$$
\begin{aligned}
\dot{m}_{\text {air }} e x_{2 \mathrm{a}}+\dot{m}_{\text {fuel }} e x_{\text {fuel }} & =\dot{m}_{\mathrm{g}} e x_{3}+I_{\text {comb }} \\
e x_{\text {fuel }} & =e x_{\mathrm{ph}, \mathrm{f}}+e x_{\mathrm{ch}, \mathrm{f}} \\
e x_{\mathrm{ch}, \mathrm{f}} & =\zeta(\mathrm{LHV})_{\text {fuel }}
\end{aligned}
$$

For the fuels with $\mathrm{C}_{x} \mathrm{H}_{y}$ compounds [19]:

$$
\zeta=1.22+0.0169 \frac{y}{x}-\frac{0.0698}{x}
$$


Gas turbine exergy:

$$
\begin{aligned}
\dot{m}_{\mathrm{g}} e x_{3} & =\dot{m}_{\mathrm{g}} e x_{5 \mathrm{a}}+\dot{W}_{\mathrm{LPT}, \mathrm{a}}+I_{\mathrm{turb}} \\
\eta_{\mathrm{II}, \mathrm{turb}} & =\frac{\dot{W}_{\mathrm{turb}}}{\dot{W}_{\mathrm{turb}}+I_{\mathrm{turb}}}
\end{aligned}
$$

Steam generator exergy

$$
\begin{aligned}
I_{\mathrm{HRSG}}= & \dot{m}_{\mathrm{gas}}\left[\left(h_{5 \mathrm{a}}-T_{0} s_{5 \mathrm{a}}\right)-\left(h_{8}-T_{0} s_{8}\right)\right] \\
& +\dot{m}_{\mathrm{st}}\left[\left(h_{12}-T_{0} s_{12}\right)-\left(h_{9}-T_{0} s_{9}\right)\right] \\
\eta_{\mathrm{II}, \mathrm{HRSG}}= & \frac{\dot{m}_{\mathrm{st}}\left[\left(h_{12}-T_{0} S_{12}\right)-\left(h_{9}-T_{0} S_{9}\right)\right]}{\dot{m}_{\mathrm{gas}}\left[\left(h_{5 \mathrm{a}}-T_{0} S_{5 \mathrm{a}}\right)-\left(h_{8}-T_{0} S_{8}\right)\right]}
\end{aligned}
$$

\subsection{Exergoeconomic analysis of combined cycle}

The conventional energy analysis does not provide any information about economical evaluations but essential to design the cost-effective systems. By combination of exergy analysis and economics the new branch of engineering called thermo economic is developed. The term exergoeconomics can also be utilized to explain the conformation of exergy analysis and economics [20]. Exergy destructions and exergy losses are used to evaluate the thermodynamic deficiencies and their costs. Knowledge of these costs is very useful for improving the cost effectiveness of the system that is, for reducing the costs of the final products produced by the system [21]. In steady state thermodynamic system, a cost balance equation for the economic analysis is as follows:

$$
\dot{C}_{\mathrm{P}, \text { total }}=\dot{C}_{\mathrm{F}, \text { total }}+\dot{Z}_{\text {total }}^{\mathrm{Cl}}+\dot{Z}_{\text {total }}^{\mathrm{OM}}
$$

The cost balance shows that the cost rate related with the product of the system $\left(\dot{C}_{\mathrm{P}}\right)$ equals the total rate of expenditures made to generate the product, namely the fuel cost rate $\left(\dot{C}_{\mathrm{F}}\right)$ and the cost rates associated with capital investment $\left(\dot{Z}_{\text {total }}^{\mathrm{Cl}}\right)$ and operating and maintenance $\left(\dot{Z}_{\text {total }}^{\mathrm{OM}}\right)$. The variable $(\dot{C})$ denotes a cost rate associated with an exergy stream: stream of matter, power, or heat transfer while the variable $(\dot{Z})$ represents all remaining costs.

In exergy costing a cost is associated with each exergy stream. Thus, for entering and exiting streams of matter with associated rates of exergy transfer and power and the exergy transfer rate associated with heat transfer, respectively [22].

$$
\begin{aligned}
\dot{C}_{i} & =c_{i} \dot{E}_{i}=c_{i}\left(\dot{m}_{i} e_{i}\right) \\
\dot{C}_{e} & =c_{e} \dot{E}_{e}=c_{e}\left(\dot{m}_{e} e_{e}\right) \\
\dot{C}_{w} & =c_{w} \dot{E}_{w} \\
\dot{C}_{q} & =c_{q} \dot{E}_{q}
\end{aligned}
$$

Exergy costing involves cost balances usually formulated for each component separately. A cost balance applied to the kth system component shows that the sum of cost rates associated with all exiting exergy streams equals the sum of cost rates of all entering exergy streams plus the appropriate charges due to capital investment $\left(Z_{k}^{\mathrm{Cl}}\right)$ and operating and maintenance expenses $\left(\dot{Z}_{k}^{\mathrm{OM}}\right)$. The sum of the last two terms is denoted by $\left(\dot{Z}_{k}\right)$. Accordingly, for a component receiving a heat transfer and generating power [23]:

$$
\sum_{e} \dot{C}_{e, k}+\dot{C}_{w, k}=\dot{C}_{q, k}+\sum_{i} \dot{C}_{i, k}+\dot{Z}_{k}
$$

Introducing the cost rate expression of Equation (39)-(42), Equation (43) becomes:

$$
\sum\left(c_{e} \dot{E}_{e}\right)_{k}+c_{w, k} \dot{W}_{k}=c_{q, k} \dot{E}_{q, k}+\sum\left(c_{i} \dot{E}_{i}\right)_{k}+\dot{Z}_{k}
$$

Using Equation (44) in every combined cycle component, the following relations emerge:

$$
\begin{aligned}
c_{\mathrm{comp}} \dot{W}_{\mathrm{comp}} & =c_{2} \dot{E} x_{2}-c_{1} \dot{E} x_{1}-\dot{Z}_{\mathrm{comp}} \\
0 & =c_{3} \dot{E} x_{3}-c_{2} \dot{E} x_{2}-c_{\mathrm{fuel}} \dot{E} x_{\mathrm{fuel}}-\dot{Z}_{\mathrm{comb}} \\
c_{\mathrm{HPT}} \dot{W}_{\mathrm{HPT}} & =c_{4} \dot{E} x_{4}-c_{3} \dot{E} x_{3}-\dot{Z}_{\mathrm{HPT}} \\
c_{\mathrm{LPT}} \dot{W}_{\mathrm{LPT}} & =c_{5} \dot{E} x_{5}-c_{4} \dot{E} x_{4}-\dot{Z}_{\mathrm{LPT}} \\
0 & =c_{8} \dot{E} x_{8}-c_{9} \dot{E} x_{9}-c_{5} \dot{E} x_{5}-c_{12} \dot{E} x_{12} \\
-c_{\mathrm{Cond}} \dot{E} x_{\mathrm{Cond}} & =c_{11} \dot{E} x_{11}-c_{10} \dot{E} x_{10}-\dot{Z}_{\mathrm{Cond}} \\
c_{\mathrm{pump}} \dot{W}_{\mathrm{pump}} & =c_{12} \dot{E} x_{12}-c_{11} \dot{E} x_{11}-\dot{Z}_{\mathrm{pump}} \\
c_{\text {fuel }} \dot{E} x_{\text {fuel }} & =C_{\text {fuel }}
\end{aligned}
$$

The following relations are used to calculate the capital cost flow [24]:

$$
\begin{aligned}
\dot{Z}_{k} & =Z_{k} C R F \phi /(N \times 3600) \\
C R F & =\frac{i(i+1)^{n}}{(i+1)^{n}-1}
\end{aligned}
$$

In which $i$, is the interest rate and $n$ is the total operating period of the system in years. $N$ is the annual number of the operation hours of the unit, and $\varphi$ (1.06) is the maintenance factor.

The second law efficiency of the combined cycle is obtained from Equation (56).

$$
\eta_{\mathrm{II}, \text { combined cycle }}=\frac{\dot{E} x_{\mathrm{w}, \mathrm{net}}}{\dot{E} x_{\text {in }}}=\frac{\dot{W}_{\mathrm{LPT}}+\dot{W}_{\mathrm{ST}}-\dot{W}_{\mathrm{pump}}}{\dot{E} x_{1}+\dot{E} x_{\mathrm{fuel}}}
$$

\section{Result of the model and discussion}

\subsection{Energy analysis}

In this research the effects of inlet air temperature, gas turbine load, pinch point and steam injection into the combustor on performance parameters of the gas turbine cycle as well as mass flow rates, power productions, temperatures, heat transfers and efficiencies have been studied. Table 4 shows the brief results of these inquiries. 
M. Javadzadeh et al.: Mechanics \& Industry 16, 510 (2015)

Table 4. Effects of inlet air temperature, load, pinch point and steam injection on combined cycle.

\begin{tabular}{cccccccccccc}
\hline Parameter & \multicolumn{3}{c}{ Inlet air } & & Load & & & Pinch point & & Injected \\
& temperature $\left(T_{1}\right)$ & & & & & & & 0 \\
steam
\end{tabular}

\subsubsection{Effects of inlet air temperature}

As Table 4 reveals, increase of gas turbine inlet air temperature in constant fuel consumption, reduces the mass flow rate of inlet air. It happens due to the decrease in air density following the increase of air temperature. By reducing the mass flow rate of the inlet air to the air compressor, its power consumption at constant speed decreases while the gas turbine fuel consumption is constant. On the other hand, because the power production of the gas turbine is directly correlated to its mass flow rate, with reduction of the air mass flow rate, the net power production of the gas turbine slakes. Furthermore, reduction in the mass flow rate of the inlet air, in the fixed fuel consumption, augments the equivalence ratio and the temperature of the combustion products, which causes the increscent of the gas turbine inlet gases and the exhaust gases temperatures. By increasing the exhaust temperature, hot gases' temperatures entering the steam generator increase, which augments the produced steam. Increasing the mass flow rate of steam, leads to the increscent of absorbed energy through vapour from hot gases which decrease the temperature of outgoing hot gases from the steam generator. This causes the augmentation of super heated steam temperature and the steam turbine produced power. By increasing the enthalpy of the steam entering the steam turbine, the temperature of leaving flow at the steam turbine fixed isentropic efficiency increases, which leads to the increment of the heat transfer in the condenser. By reducing the output power of the gas turbine at constant fuel consumption, gas tur- bine cycle efficiency decreases, but with the increase of power production of the steam turbine, the efficiency of the combined cycle almost remains constant.

\subsubsection{Effects of the load}

Increasing the load of the gas turbine, increases the fuel consumption and the turbine inlet gas temperature. Augmentation of fuel at the consumption of constant air, would increase the temperature of combustion products which increases the temperature of all point at the combined cycle, but same as the previous situation, the steam generator's outlet temperature would decrease due to the increase in absorbed energy through vapour from hot gases. More over the efficiency of combined cycle would upraise as a result of the ascending the power production of the turbine.

\subsubsection{Effects of the pinch point}

The pinch point is one of the main parameters in designing of heat recovery steam generator which affects the performance of the steam production cycle. As it is shown in Table 4 the parameters of the gas turbine cycle, for different values of the pinch points are fixed, but the parameters of steam cycle performance, with the variation of pinch points are changed. The ascending of the pinch point means the reduction in energy transfer capability from hot gases into the steam generator. As it can be 
seen in the table, with increase of pinch point from $10{ }^{\circ} \mathrm{C}$ to $50{ }^{\circ} \mathrm{C}$ the amount of produced steam decreases from $6.837 \mathrm{~kg} . \mathrm{s}^{-1}$ to $5.989 \mathrm{~kg} . \mathrm{s}^{-1}$. The reduction of produced steam would decrease the steam turbine power, the efficiency of the combined cycle and the rate of heat transfer in the steam generator and condenser.

\subsubsection{Effects of steam injection}

Steam injection to the gas turbine combustor is considered as one of the most efficient methods to improve the performance of gas turbines. Table 4 shows the effects of steam injection into the gas turbine combustor on combined cycle performance parameters. In these investigation parameters such as the inlet air temperature, the mass flow rate of the air compressor, the gas turbine net power production and the pinch point are considered to be constant. With increasing the mass flow rate of steam injected into the combustion chamber, the total mass flow of the gas turbine augments. Since the production power of gas turbine is directly affected by the mass flow rate, so the ascending of the mass flow rate would increase the net power production of the gas turbine. Therefore to maintain the production power of the gas turbine, the inlet fuel energy should be reduced along with the increase of the steam injection. The superheated steam is injected in to the compressed air and the mixture of steam and air enters the combustion chamber. Since the temperature of steam is lower than the temperature of the compressed air the air/steam mixture temperature decreases. Also the reduction of fuel consumption in the gas turbine constant net power production would reduce the temperature of the combustion products which causes to decrease the turbine inlet gases and the exhaust gases temperature. Decreasing the HRSG inlet gases temperature, reduces the mass flow rate of produced steam which causes the increase in HRSG outgoing gases temperature due to the reduction of absorbed energy from the vapour. Furthermore, decreasing in the steam mass flow rate reduces the steam turbine power production and the heat transfer rate in the condenser. The important point in this issue is the rise of the efficiency of the gas turbine cycle and combined cycle by increasing the injection of steam into the gas turbine combustion chamber. As it is revealed in the results, with increasing the steam injection from $0 \mathrm{~kg} . \mathrm{s}^{-1}$ to $0.5 \mathrm{~kg} . \mathrm{s}^{-1}$ in the fixed net power production of the gas turbine, the steam turbine power production would decrease from 648 to $460 \mathrm{~kW}$. This only does not reduce the efficiency of the combined cycle but it also raises it from 34 to 37.5 percent. This happens because of the reduction in the inlet energy of burnt fuel in the gas turbine combustion chamber according to Equations (22) and (23).

\subsection{The exergy-economy analysis}

In this part of the study the combined cycle is investigated from the exergy and economy point. Table 5 shows
Table 5. The exergy rate, cost flow rate and unit exergy cost at various pipelines.

\begin{tabular}{cccc}
\hline & $E x$ & $C$ & $c$ \\
\hline Pipe No. & {$[\mathrm{kW}]$} & {$\left[\$ . \mathrm{h}^{-1}\right]$} & {$\left[\$ . \mathrm{kw}^{-1} \cdot \mathrm{h}^{-1}\right]$} \\
\hline 1 & 8.04 & 0 & 0 \\
2 & 15715 & 770.8 & 0.04905 \\
3 & 39108 & 1547 & 0.03955 \\
4 & 20804 & 822.9 & 0.03955 \\
5 & 8556 & 338.4 & 0.03955 \\
8 & 266.9 & 10.56 & 0.03955 \\
9 & 7338 & 359.2 & 0.04895 \\
10 & 5897 & 288.7 & 0.04895 \\
11 & 534.3 & 26.15 & 0.04895 \\
12 & 541.1 & 26.49 & 0.04895 \\
fuel & 35975 & 771.1 & 0.02143 \\
\hline
\end{tabular}

Table 6. Natural gas compositions.

\begin{tabular}{|c|c|c|}
\hline Component & $\begin{array}{c}\text { Mole fraction } \\
(\%)\end{array}$ & $\begin{array}{c}\text { Mass fraction } \\
(\%)\end{array}$ \\
\hline $\mathrm{CH}_{4}$ & 89.5650 & 80.3470 \\
\hline $\mathrm{C}_{2} \mathrm{H}_{6}$ & 3.3060 & 5.5587 \\
\hline $\mathrm{C}_{3} \mathrm{H}_{8}$ & 1.1320 & 2.7912 \\
\hline $\mathrm{C}_{4} \mathrm{H}_{10}$ & 0.3020 & 0.9815 \\
\hline $\mathrm{i}-\mathrm{C}_{4} \mathrm{H}_{10}$ & 0.2320 & 0.7540 \\
\hline $\mathrm{C}_{5} \mathrm{H}_{12}$ & 0.0460 & 0.185 \\
\hline $\mathrm{i}-\mathrm{C}_{5} \mathrm{H}_{12}$ & 0.0690 & 0.2783 \\
\hline neo- $\mathrm{C}_{5} \mathrm{H}_{13}$ & 0.0030 & 0.00 \\
\hline $\mathrm{C}_{6} \mathrm{H}_{14}$ & 0.0710 & 0.00 \\
\hline $\mathrm{N}_{2}$ & 4.7300 & 7.4103 \\
\hline $\mathrm{CO}_{2}$ & 0.5440 & 1.3388 \\
\hline
\end{tabular}

the exergy rate, cost flow rate and the unit exergy cost in various pipelines. The natural gas is the fuel of interest, with the composition shown in Table 6 and with the mass flow rate and the temperature of $2592 \mathrm{~kg} \cdot \mathrm{h}^{-1}$ and $298 \mathrm{~K}$ respectively. The highest amount of exergy and exergy cost are in the products of the combustion which come out of the combustion chamber. This is due to the high temperature of the releasing of chemical energy of the fuel. These results are for the situation that there is no steam injection to the combustion chamber and the pinch point is equal $10 \mathrm{~K}$. By applying the exergy-economy balance equation, for the existing equipments in the combined cycle and simultaneous solution of them, various amounts of the unit exergy cost in different parts of the cycle are obtained. Furthermore, effects of the inlet air temperature, pinch point and steam injection are investigated on irreversibility fractions and exergy costs in different parts of the combined cycle.

\subsubsection{Effects of inlet air temperature on the irreversibilities and cost flow rate}

Figure 4 shows the irreversibility fractions of combined cycle components obtained in various inlet air temperatures. In this case the fuel mass flow rate is $2596 \mathrm{~kg} . \mathrm{s}^{-1}$ and the pinch point is equal to $10 \mathrm{~K}$ without any steam injections. With increasing the inlet air temperature the gas 


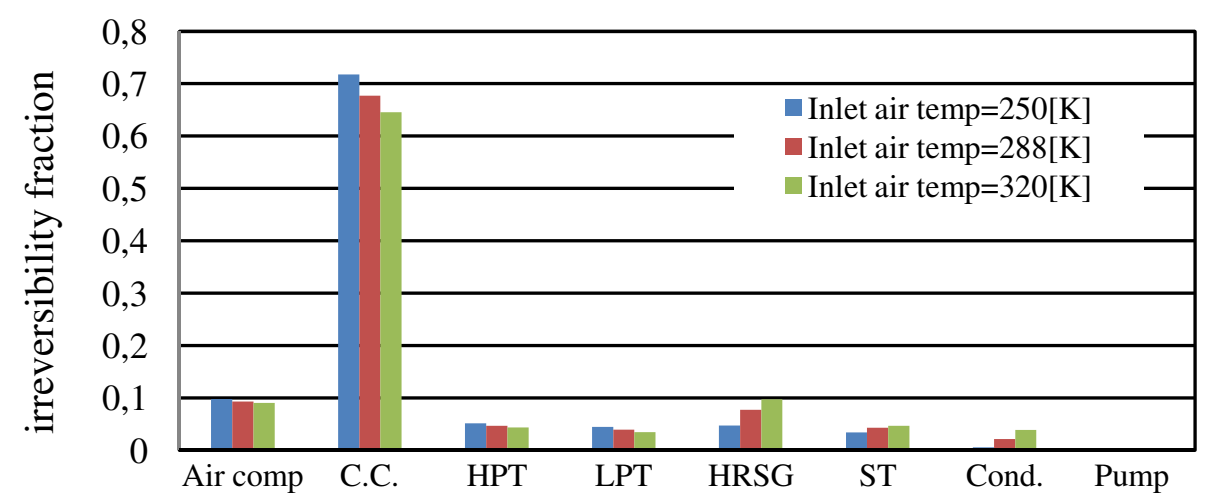

Fig. 4. Irreversibility fractions of combined cycle components for various inlet air temperatures.

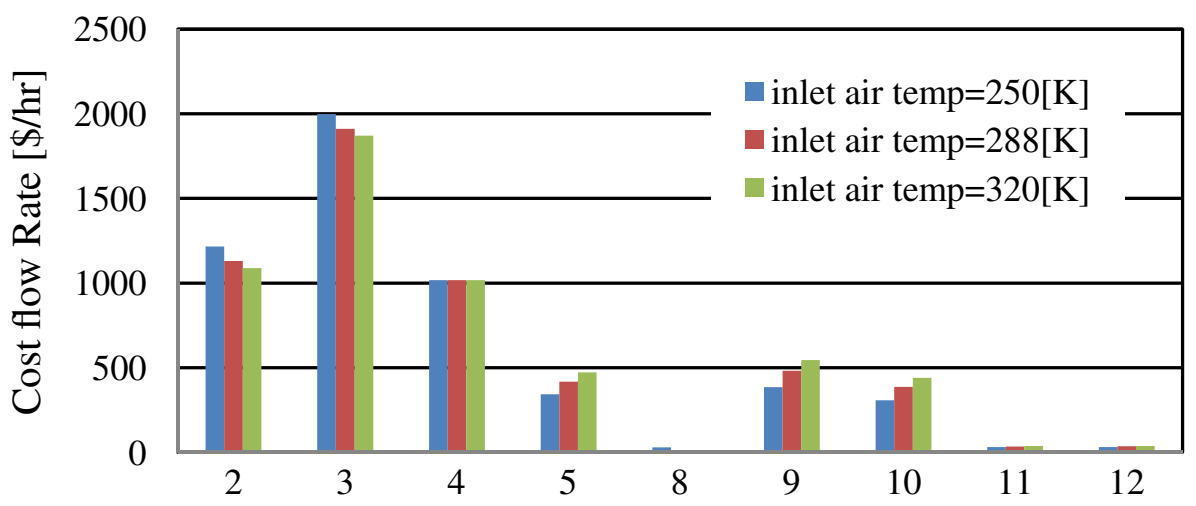

Fig. 5. Cost flow rate for the combined cycle pipelines for various inlet air temperatures.

turbine cycle components irreversibilities decrease while the bottoming cycle increases due to the increase in the steam mass flow rate.

Figure 5 shows the cost flow rate for the combined cycle pipelines. The cost flow rate in the gas turbine cycle pipelines has decreased in higher inlet air temperature while the bottoming cycles' have increased. In this regard following points can be mentioned:

1. With increasing the inlet air temperature the mass flow rate of the inlet air decreases so the total exergy of the point 2 reduces. In addition the unit exergy cost reduces and the cost flow rate of point 2 reduces according to Equation (40).

2. The combustion products temperature increases by increasing the inlet air temperature. But the unit exergy cost reduces and causes to reduce the cost flow rate of point 3 . The unit exergy cost for the $250 \mathrm{~K}, 288 \mathrm{~K}$ and $320 \mathrm{~K}$ inlet air temperatures are equal to $0.07656 \$ . \mathrm{kw}^{-1} \cdot \mathrm{h}^{-1}, 0.07189 \$ . \mathrm{kw}^{-1} \cdot \mathrm{h}^{-1}$ and $0.06853 \$ . \mathrm{kw}^{-1} \cdot \mathrm{h}^{-1}$ respectively.

3. Points 4 and 5 are similar to point 3 . But in point 4 according to the decrease in unit exergy cost and increase in total exergy the cost flow rate remains constant in Equation (40). But in point 5 the exergy increase is greater than the decrease in the value of the unit exergy cost so the cost flow rate increases.

4. In the pipeline 8 the temperature of the gases decreases according to the results of Table 4 . The reduction in the temperature and in the mass flow rate decreases the cost flow rate of point 8 .

5. In the other pipelines (9-10-11-12) according to the increase in exhaust gasses temperature by increasing the inlet air temperature the steam mass flow rate and temperature increase and these cause to increase in the cost flow rate of bottoming cycle pipelines.

\subsubsection{Effects of pinch point on the irreversibilities and cost flow rates}

Figure 6 shows the effects of the pinch point on the irreversibility fractions of bottoming cycle. The running conditions of the combined cycle are similar to the previous section but with various pinch points. Since the pinch point does not affect the gas turbine cycle parameters so the gas turbine cycle components are not considered in this section. It is seen that with increasing the pinch point the irreversibility of HRSG increases while the others decrease.

This is due to the steam mass flow rate. The gas turbine cycle mass flow rate entering to the HRSG is constant. By increasing the pinch point the steam mass flow decreases. The reduction of steam mass flow rate increases the HRSG irreversibility in Equation (36). On the other hand the irreversibility fractions of the steam turbine, condenser and pump decrease due to the reduction of steam mass flow rate. 


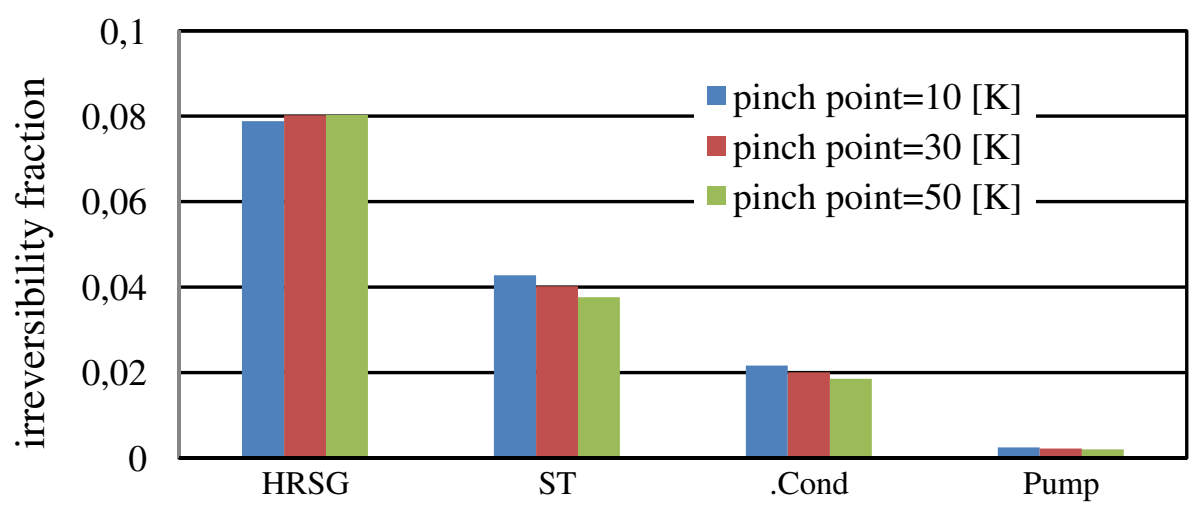

Fig. 6. Effects of the pinch point on the irreversibility fractions of bottoming cycle.

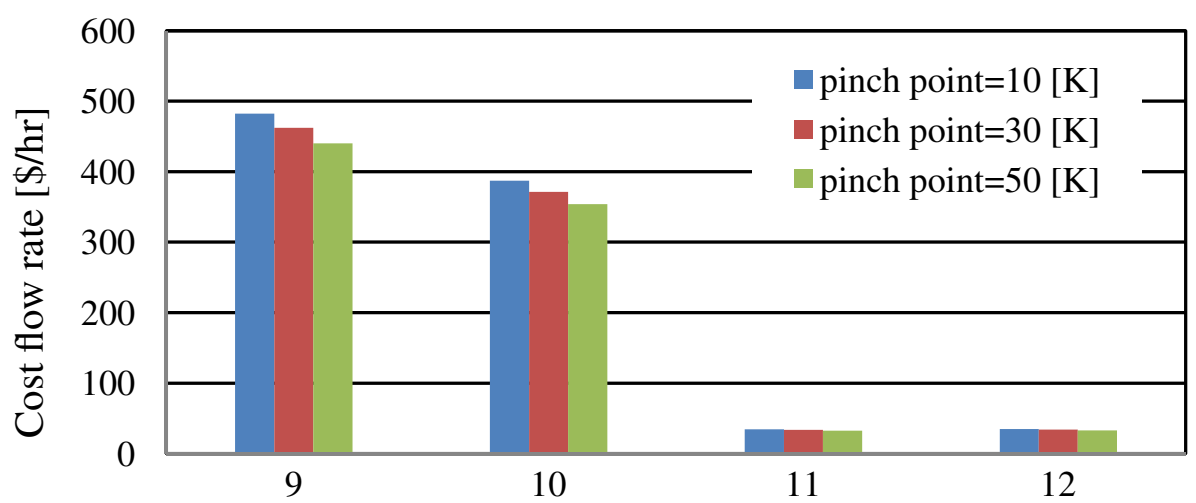

Fig. 7. Effects of the pinch point on the cost flow rate of the bottoming cycle .

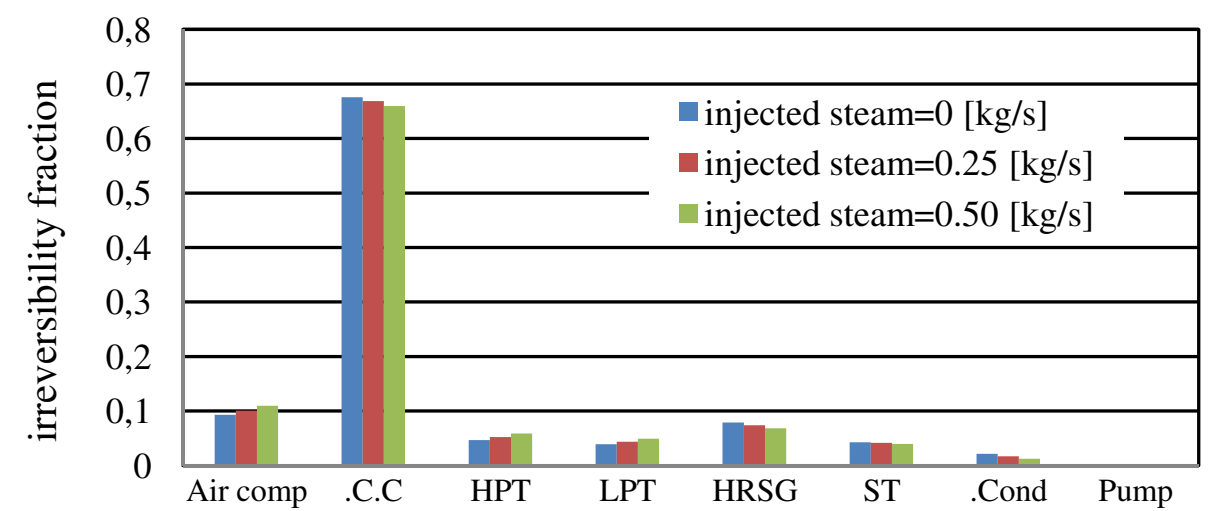

Fig. 8. Irreversibility fractions of the combined cycle components for various steam injections.

Figure 7 shows the effects of the pinch point on the cost flow rate of the bottoming cycle. Increasing the pinch point in the HRSG reduces the energy absorption of generated steam from entering hot gasses. So the produced steam mass flow rate decreases. The reduction of steam mass flow rate reduces the exergy in all bottoming cycle pipelines and decreases the cost flow rates.

\subsubsection{Effects of steam injection on the irreversibilities and cost flow rates}

Figure 8 shows the irreversibility fractions of the combined cycle components for various steam injections. In this case the inlet air temperature and the fuel mass flow rate and the pinch point are considered $288 \mathrm{~K}$, $2596 \mathrm{~kg} \cdot \mathrm{h}^{-1}$ and $10 \mathrm{~K}$ respectively. Increasing in the injected steam in to the combustion chamber led to decrease in some components and increase in others. But the overall irreversibly of the combined cycle reduced from $18621 \mathrm{~kW}$ to $18463 \mathrm{~kW}$ by $0.5 \mathrm{~kg} . \mathrm{s}^{-1}$ steam injection.

Figure 9 shows the cost flow rate of the combined cycle pipelines for various steam injections. In this case the net power production of the gas turbine is kept constant by reducing the fuel consumption. The inlet air temperature is $288 \mathrm{~K}$ and the pinch point is $10 \mathrm{~K}$. According to the results of Table 4 the air compressor power absorption 


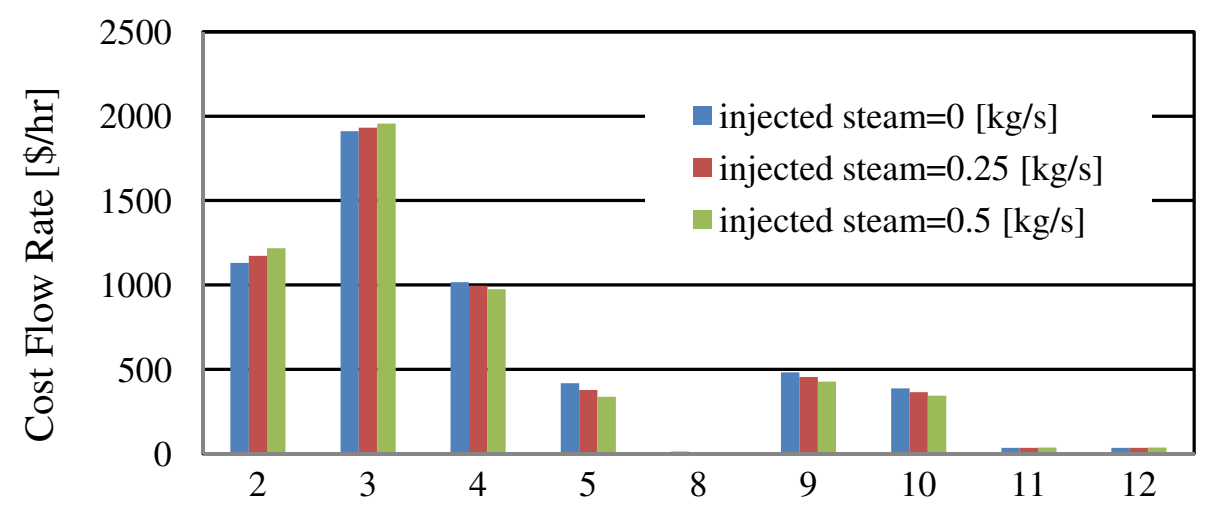

Fig. 9. Cost flow rate of the combined cycle pipelines for various steam injections.

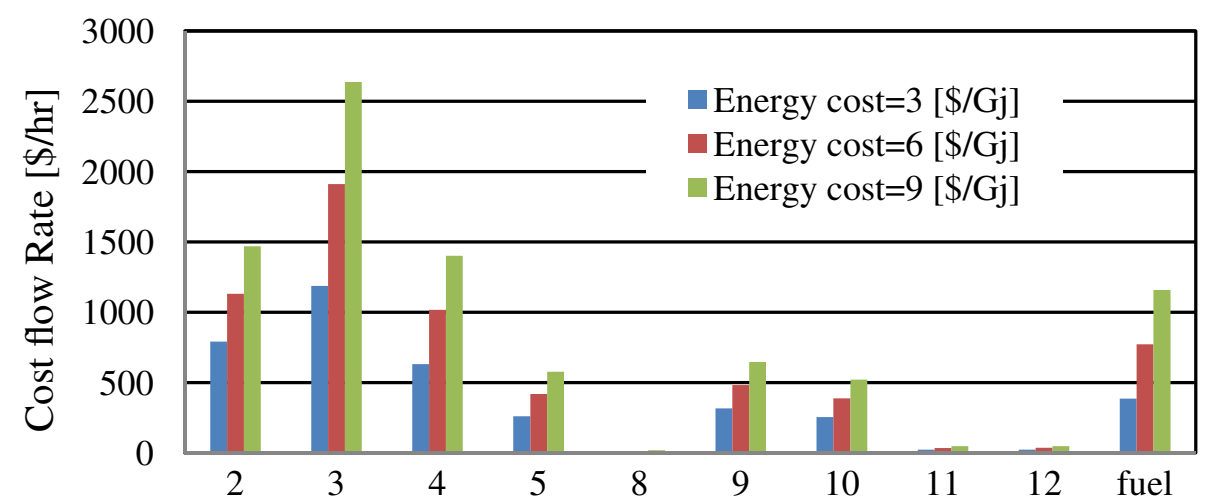

Fig. 10. Effects of energy price on the cost flow rates of the combined cycle.

increases by steam injection. This increases the exergy and the cost flow rate of point 2 . In pipeline 3 the total exergy reduces due to the temperature reduction. But unit exergy cost increases and raises the cost flow rate according to Equation (40). The reduction of the temperature in the gas turbine cycle and steam mass flow rate in bottoming cycle are the main reasons for the cost flow rate reduction in other points of the combined cycle.

\subsubsection{Effects of energy price on the cost flow rates}

Figure 10 illustrates the effects of energy price on the cost flow rates of the combined cycle pipelines in the condition of $288 \mathrm{~K}$ inlet air temperature, no steam injection, $10 \mathrm{~K}$ pinch point and $2596 \mathrm{~kg} \cdot \mathrm{h}^{-1}$ fuel consumption. As shown in the figure increasing the energy price in the exergoeconomics equations increases the cost flow rate of all pipelines.

\subsection{Investment recovery considerations}

One of the most important approaches of the present study is to replace the existing inefficient starting system with other starting methods and use of electrical energy of steam turbine in the gas turbine auxiliary equipments. It is clear that this proposed system is profitable in the
Table 7. Electrical power consumption for gas turbine auxiliary equipments in full load.

\begin{tabular}{ccc}
\hline & No. (In 1 gas turbine) & Power [kW] \\
\hline Gas Coolers & 4 & 37 \\
Ventilation Fans & 2 & 26 \\
Oil Coolers & 2 & 8.8 \\
Vapour Separator & 1 & 5.5 \\
Total & 223 & \\
\hline
\end{tabular}

steady state running conditions. The electrical power consumptions for the gas turbine auxiliary equipments in full load are summarized in Table 7 .

The present gas turbine starting system, is an expansion turbine with the working fluid of natural gas. In this system the high pressure gas enters the starter turbine in the appropriate pressure and temperature and drives the turbine and then is vent to the atmosphere. In Table 8 the amounts of consumed natural gas in each start process are illustrated respectively.

Starting process of the gas turbine consists of three main sections including start up, purge and fire and the mass flow rate of the natural gas in each stage is different. It's important to mention that the same mechanism is used crank the air compressor in washing process which wastes much more gas according to the washing duration and mass flow rate. In Table 9 the price of unit energy, amount of wasted natural gas in starting and washing, 
M. Javadzadeh et al.: Mechanics \& Industry 16, 510 (2015)

Table 8. Natural gas consumption for pneumatic starter (per one attempted).

\begin{tabular}{|c|c|c|c|c|c|c|c|c|c|}
\hline & & \multicolumn{2}{|c|}{ Flow } & \multicolumn{2}{|c|}{ Duration } & \multicolumn{2}{|c|}{ Consumption } & \multirow{3}{*}{ Pressure } & \multirow{3}{*}{ Temperature } \\
\hline & Start & For & For & For & For & For & For & & \\
\hline & \multirow[t]{2}{*}{ Sequence } & Starting & Washing & Starting & Washing & Starting & Washing & & \\
\hline & & $\mathrm{kg} \cdot \mathrm{h}^{-1}$ & $\mathrm{~kg} \cdot \mathrm{h}^{-1}$ & $\min$ & $\min$ & $\mathrm{kg}$ & $\mathrm{kg}$ & bar & ${ }^{\circ} \mathrm{C}$ \\
\hline 1 & Start Up & 18820 & & 7 & & 2196 & & \multirow{4}{*}{27 to 30} & \multirow{4}{*}{15} \\
\hline 2 & Purge & 12000 & 12000 & 2 & 20 & 400 & 4000 & & \\
\hline 3 & Fire & 12000 & & 0.5 & & 100 & & & \\
\hline \multicolumn{6}{|c|}{ Total Natural Gas Consumption } & 2696 & 4000 & & \\
\hline
\end{tabular}

the price of electrical power consumption of auxiliaries and fuel consumption are calculated.

The starting turbine is basically a steam turbine and is designed for the working fluid of super heated steam. It is proposed to use it in bottoming cycle to produce electrical power in steady state running and independent the gas turbine unit from external electrical energy and return the surplus amount of electrical power to the urban power network.

As discussed in the previous section steam injection to the combustion chamber of the gas turbine led to increase in combined cycle efficiency and reduced in the gas turbine fuel consumption.

In Table 10 the fuel consumption, steam turbine power production and the price of energy rates are calculated for various steam injections. With increasing the steam injection to the combustion chamber the steam turbine power production decreases due to the reduction of the steam mass flow rate, on the other hand the fuel consumption decreases by steam injection in gas turbine constant load. The results reveal that the cost of saved fuel through the steam injection is greater than the reduction of the steam turbine power production price. So when the gas turbine is running in full load in the proposed system, by injection of $0.5 \mathrm{~kg} . \mathrm{s}^{-1}$ steam to the combustion chamber 61920 dollars will be saved monthly for every turbo compressor unit. Since the studied gas compression station is designed in the formation of $4+1$ (4 units running and 1 standby) in the case of utilizing the proposed system, 247680 dollars will be saved monthly. All these calculations are based on the gas compressors maximum power absorptions from the gas turbine in the real working condition of the plant.

\section{Conclusions}

In the present research we discuss the use of HRSG system in Marand gas compression station in order to utilize the gas turbines exhaust gas energies to produce electrical power in order to make independent the gas turbine unit from external electrical energy investigated and the effects of inlet air temperature, pinch point, turbine load and steam injection to the combustion chamber on the combined cycle parameters studied. Also the prices of savings according to the production of power in steam turbine and reduction of fuel consumption through steam
Table 9. Energy and natural gas price per one start.

\begin{tabular}{lc}
\hline Energy price $\$ . \mathrm{GJ}^{-1}$ & 6 \\
Low heat value $\mathrm{kj}_{\mathrm{kg}} \mathrm{kg}^{-1}$ & 49580 \\
NG price $\$ . \mathrm{kg}^{-1}$ & 0.2975 \\
NG price during start $\$$ & 802 \\
NG price during washing $\$$ & 1190 \\
Turbine facilities $\$ . \mathrm{h}^{-1}$ & 4.82 \\
Fuel consumption $\$ . \mathrm{h}^{-1}$ & 771.12 \\
\hline
\end{tabular}

injection are considered. The most important results from this research are:

1. Increasing the inlet air temperature in the constant fuel consumption, reduced the gas turbine net power production, and combined cycle efficiencies. On the other hand the exhaust gasses temperature through the reduction of the air compressor mass flow rate increased. Increased exhaust gasses temperature led to increase the generated steam mass flow rate in HRSG and then the produced power in the steam turbine increased. In addition the irreversibilities of the gas turbine cycle decreased while the irreversibility of the bottoming cycle increased.

2. Increase in the load of the gas turbine, increased the fuel consumption, gas turbine and steam turbine power productions and the efficiencies of the gas turbine and combined cycle for the air compressor constant mass flow rate.

3. Increasing in the pinch point did not affect the gas turbine cycle but reduced the steam turbine power production and bottoming cycle efficiency. In addition in HRSG the irreversibilities increased but it reduced in steam turbine, condenser and pump while it was constant in gas turbine cycle.

4. The steam injection to the combustion chamber in the gas turbine constant power production, reduced the fuel consumption, combustion products and exhaust gases temperatures, generated steam mass flow rate in HRSG and steam turbine power production. But the efficiencies of the gas turbine cycle and the bottoming cycle increased because of the reduction of the fuel inlet energy.

5. The results indicate that replacing the inefficient existing starting system will save $2696 \mathrm{~kg}$ of natural gas valued at 802 dollars in each start process. Due to the power requirements at the moment of start of the gas 
Table 10. Steam turbine power generation prices.

\begin{tabular}{cccccccc}
\hline$\dot{m}_{\text {steam }}$ & $\dot{m}_{\text {fuel }}$ & GT net power & $\dot{w}_{\text {steam }}$ & $\dot{w}_{\text {steam }}$ & $\begin{array}{c}\text { Price of electrical } \\
\text { power production }\end{array}$ & $\begin{array}{c}\text { Price of fuel saved } \\
\text { through steam inj. }\end{array}$ & $\begin{array}{c}\text { Total energy } \\
\text { saving Price }\end{array}$ \\
\hline$\left[\mathrm{kg} . \mathrm{s}^{-1}\right]$ & {$\left[\mathrm{kg} . \mathrm{s}^{-1}\right]$} & {$[\mathrm{kW}]$} & {$\left[\mathrm{kW} \cdot \mathrm{h}^{-1}\right]$} & GJ per hour & $\$ . \mathrm{h}^{-1}$ & $\$ . \mathrm{h}^{-1}$ & \\
\hline 0 & 0.5684 & 8000 & 454.8 & 1.63728 & 9.82368 & 0 & 9.82368 \\
0.1 & 0.5512 & 8000 & 417.2 & 1.50192 & 9.01152 & 18.4212 & 27.43272 \\
0.2 & 0.536 & 8000 & 383.7 & 1.38132 & 8.28792 & 34.7004 & 42.98832 \\
0.25 & 0.5278 & 8000 & 366.7 & 1.32012 & 7.92072 & 43.4826 & 51.40332 \\
0.3 & 0.5203 & 8000 & 351 & 1.2636 & 7.5816 & 51.5151 & 59.0967 \\
0.35 & 0.5165 & 8000 & 343.2 & 1.23552 & 7.41312 & 55.5849 & 62.99802 \\
0.4 & 0.5087 & 8000 & 327.6 & 1.17936 & 7.07616 & 63.9387 & 71.01486 \\
0.45 & 0.502 & 8000 & 313.5 & 1.1286 & 6.7716 & 71.1144 & 77.886 \\
0.5 & 0.494 & 8000 & 298.1 & 1.07316 & 6.43896 & 79.6824 & 86.12136 \\
\hline
\end{tabular}

turbine the electric motor with power consumption of about $110 \mathrm{~kW}$ can be one of the best options to replace the existing system. In this case the total amount of energy consumption price is about 0.8 dollars in each starting attempt. In addition one can start up the present starting unit with the electrical power of the further started unit

6. The reduction in the fuel consumption by injecting the steam in to the combustion chamber of the gas turbine in the maximum required load, led to economic savings equivalent to 79.68 dollars for an hour work of a gas turbine unit. When the station is running in its full load and design condition the amount of economic savings will exceed to 247000 dollars in month

Acknowledgements. The authors express their great appreciation to the financial support by the National Iranian Gas Company-Gas Transport Operations Destination 8.

\section{References}

[1] H. Kum, O. Ocal, A. Aslan, The relationship among natural gas energy consumption, capital and economic growth: Bootstrap-corrected causality tests from G-7 countries, Renew. Sust. Energ. Rev. 16 (2012) 2361-2365

[2] Deng-Chern Sue, Chia-Chin Chuang, Engineering design and exergy analyses for combustion gas turbine based power generation system, Energy 29 (2004) 1183-1205

[3] F.J. Wang, J.S. Chiou, P.C. Wu, Economic feasibility of waste heat to power conversion, Appl. Energ. 84 (2007) 442-454

[4] Cheng Yang, Zeliang Yang, Ruixian Cai, Analytical method for evaluation of gas turbine inlet air cooling in combined cycle power plant, Appl. Energ. 86 (2009) 848856

[5] Jong Jun Lee, Mu Sung Jeon, Tong Seop Kim, The influence of water and steam injection on the performance of a recuperated cycle micro turbine for combined heat and power application, Appl. Energ. 87 (2010) 1307-1316
[6] F. Basrawi, T. Yamada, K. Nakanishi, S. Naing, Effect of ambient temperature on the performance of micro gas turbine with cogeneration system in cold region, Appl. Thermal Eng. 31 (2011) 1058-1067

[7] F.J.G. Carazas, C.H. Salazar, G.F.M. Souza, Availability analysis of heat recovery steam generators used in thermal power plants, Energy 36 (2011) 3855-3870

[8] H. Sayyaadi, R. Mehrabipour, Efficiency enhancement of a gas turbine cycle using an optimized tubular recuperative heat exchanger, Energy 38 (2012) 362-375

[9] M. Livshits, A. Kribus, Solar hybrid steam injection gas turbine (STIG) cycle, Sol. Energ. 86 (2012) 190-199

[10] A.G. Kaviri, M. Nazri Mohd. Jaafar, T. Mat Lazim, H. Barzegaravval, Exergo environmental optimization of Heat Recovery Steam Generators in combined cycle power plant through energy and exergy analysis, Energy Convers. Manag. 67 (2013) 27-33

[11] Hongcui Feng, Wei Zhong, Yanling Wu, Shuiguang Tong, Thermodynamic performance analysis and algorithm model of multi-pressure heat recovery steam generators (HRSG)based on heat exchangers layout, Energy Convers. Manag. 81 (2014) 282-289

[12] M.J. Moran, H.N. Shapiro, Fundamentals of engineering thermodynamics, 4th edn., Wiley, New York, 2000

[13] P. Ahmadi, I. Dincer, Thermodynamic analysis and thermoeconomic optimization of a dual pressure combined cycle power plant with a supplementary firing unit, Energy Convers. Manag. 52 (2011) 2296-308

[14] H. Cohen, G. Roger, H. Saravanamottoo, Gas-turbine Theory, 4th edn., Prentice-Hall, New York, 1996

[15] R.E. Sonntag, C. Borgenakke, G.J. Van Wylen, Fundamentals of Thermodynamics, 5th edn., John Wiley \& Sons, New York, 1998

[16] R. Karthikeyan, M. Hussain, B.V. Reddy, P.K. Nag, Performance simulation of heat recovery steam generators in a cogeneration system, Int. J. Energy Res. 22 (1998) 399-410

[17] C.J. Butcher, B.V. Reddy, Second law analysis of a waste heat recovery based power generation system, Int. J. Heat Mass Transf. 50 (2007) 2355-2363 
[18] A. Bejan, Fundamental of exergy analysis, Entropy generation minimization, and the generation of flow architecture, Int. J. Energy Res. 26 (2002) 545-565

[19] G. Tsasaronis, J. Pisa, Exergoeconomic evaluation and optimization of energy systems-application to CGAM problem, Energy 19 (1994) 287-321

[20] P. Ahmadi, I. Dincer, Thermodynamic analysis and thermoeconomic optimization of a dual pressure combined cycle power plant with a supplementary firing unit, Energy Convers. Manag. 52 (2011) 2296-308

[21] A. Bejan, G. Tsatsaronis, M. Moran, Thermal Design and Optimization. Wiley, New York, 1996

[22] P. Roosen, S. Uhlenbruck, K. Lucas, Pareto optimization of a combined cycle power system as a decision support tool for trading off investment vs. operating costs, Int. J. Thermal Sci. 42 (2003) 553-560

[23] J.L. Silvera, C.E. Tuna, Thermo economic analysis method for optimization of combined heat and power systems, Part 1. Progress in Energy and Combustion Science 29 (2003) 479-485

[24] P. Roosen, S. Uhlenbruck, K. Lucas, Pareto optimization of a combined cycle power system as a decision support tool for trading off investment vs. operating costs, Int. J. Therm. Sci. 42 (2003) 553-60

[25] Dresser-Rand Company, steam products, single stage steam turbine, Available at : www.dresser-rand.com/ products/steam/singlestage/RLA.php 